\title{
Análise da expressão imuno-histoquimica de c-erbB-2 e EGFR em carcinoma epidermóide de esôfago
}

\author{
Immunohistochemical expression of c-erbB-2 and EGFR in esophageal squamous cell carcinoma
}

Yukie Sato'; Carlos Ferreira Nascimento²; Severino da Silva Ferreira; José Humberto T. G. Fregnani3; Fernando Augusto Soares ${ }^{4}$

\begin{tabular}{|c|c|}
\hline unitermos & esumo \\
\hline $\begin{array}{l}\text { Imuno-histoquímica } \\
\text { c-erbB-2 } \\
\text { EGFR } \\
\text { Tissue microarray } \\
\text { Carcinoma epidermóide } \\
\text { de esôfago }\end{array}$ & $\begin{array}{l}\text { Introdução: O carcinoma epidermóide de esôfago (CEE) possui alta incidência em nosso país, com altas } \\
\text { taxas de mortalidade. A família dos receptores do fator epitelial de crescimento (EGFR) é composta por } \\
\text { quatro membros, e muitos estudos têm sido direcionados para a expressão de EGFR e c-erbB-2, com } \\
\text { implicações terapêuticas. Objetivo: Investigar as expressões imuno-histoquímicas de EGFR e c-erbB-2 e } \\
\text { correlacioná-las a aspectos clinicopatológicos em casos de CEE. Material e métodos: Para esse estudo, } \\
\text { dados clinicopatológicos de } 613 \text { CEE foram revistos. A imunoistoquímica foi feita utilizando anticorpo } \\
\text { policlonal para c-erbB-2 e monoclonal para EGFR em } 597 \text { e } 585 \text { casos, respectivamente. Os casos } \\
\text { representados por peças cirúrgicas foram distribuídos em três blocos de parafina de tissue microarray } \\
\text { (TMA), inseridos em duplicata; aqueles com biópsias foram analisados em corte convencional. Todos } \\
\text { foram classificados de acordo com intensidade e padrão de marcação de membrana das células } \\
\text { tumorais. Resultados: As expressões de c-erbB- } 2 \text { e EGFR foram observadas em } 42,4 \% \text { e } 77,6 \% \text { dos casos, } \\
\text { respectivamente. Observou-se correlação estatisticamente significativa entre as expressões de c-erbB-2 } \\
\text { ( } p=0,04 \text { ) e EGFR ( } p=0,01 \text { ) e grau histológico. Ambos os marcadores foram significativamente mais } \\
\text { expressos em casos bem/moderadamente diferenciados do que nos pouco diferenciados/indiferenciados. } \\
\text { Embora não tenha sido significativa, houve uma tendência de associação entre superexpressão de c-erbB- } \\
2 \text { e sítio do tumor, em que casos positivos ocorreram com mais freqüência no terço médio do esôfago. } \\
\text { Nenhuma correlação significativa foi verificada entre essas proteínas e sobrevida global. Conclusão: Os } \\
\text { resultados podem sugerir um papel primordial para essas proteínas na diferenciação tumoral em CEE. }\end{array}$ \\
\hline
\end{tabular}

abstract

Introduction: Esophageal squamous cell carcinoma (ESCC) is highly prevalent in Brazil, and responsible for high mortality index. The epidermal growth factor receptor (EGFR) family has four members and much attention has been focused on the expressions of EGFR and c-erbB-2 with therapeutic implications. Objective: The aim of the present study was to investigate immunohistochemical expressions of c-erbB-2 and EGFR in ESCC, and correlate them with clinicopathological data. Material and methods: Medical records of 613 patients with ESCC were reviewed. Immunohistochemistry was carried out using polyclonal c-erbB-2 and monoclonal EGFR in 597 and 585 cases, respectively. Cases represented by surgical resections were performed in three tissue microarray (TMA) paraffin blocks spotted in duplicate; those with small biopsies without surgical resections were performed individually. All cases were scored according to intensity and pattern of membrane staining of tumor cells. Results: The expressions of c-erbB-2 and EGFR were observed in $42.4 \%$ and $77.6 \%$ of the cases, respectively. A significant correlation was found between c-erbB-2 $(p=0.04)$ and EGFR $(p=0.01)$ expressions and histological grade. Both markers were significantly more expressed in well/moderate differentiated ESCC than in poorly differentiated ESCC. Although it was not significant, there was a tendency of association between c-erbB-2 overexpression and tumor location, in which positive cases occurred more frequently in the middle third of the esophagus. There was no correlation with overall survival. Conclusion: The results may suggest a role for these markers in tumoral differentiation in ESCC. 


\section{Introdução}

O carcinoma epidermóide do esôfago (CEE) é o tipo histológico mais comum de câncer do órgão, assim como uma das neoplasias malignas mais comuns em nosso meio. Ocorre predominantemente em países em desenvolvimento e é a sexta neoplasia em freqüência em nosso país, com cerca de 10.600 casos novos por ano, causando mais de 5.300 óbitos/ano ${ }^{(18)}$. Os dados do Instituto Nacional do Câncer (INCa) mostram uma grande diferença regional em nosso país, sugerindo forte envolvimento de fatores ambientais em sua etiologia, como dieta e alto consumo de tabaco e álcool $(4,6,28)$. Outros fatores como agentes infecciosos, com ênfase no papilomavírus humano ${ }^{(2,35)}$, e síndromes como acalasia e tilose ${ }^{(3,16)}$ também têm sido implicados na gênese desse tumor.

Geralmente, o CEE está associado a um prognóstico ruim, por se tratar de um tumor em estádio avançado no momento do diagnóstico e apresentar alta freqüência de metástases linfonodais. O comprometimento linfonodal é considerado uma importante causa para o fracasso das terapias nesses tumores ${ }^{(14,25)}$. Assim, embora as várias modalidades de terapia, adicionalmente à ressecção cirúrgica, tenham sofrido melhora ao longo dos anos, ainda se observa alta taxa de mortalidade após cirurgia entre os pacientes

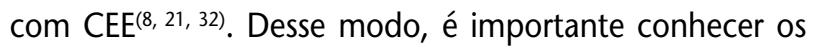
fatores prognósticos que podem auxiliar na escolha da terapia mais apropriada.

A família dos receptores dos fatores de crescimento epidérmico é um grupo bem definido de quatro moléculas homólogas que incluem o receptor do fator epitelial de crescimento (EGFR, do inglês epidermal growth factor receptor), c-erbB-2, c-erbB-3 e c-erbB-4. A importância desses receptores tem sido amplamente estudada em diversas neoplasias malignas, com ênfase nos carcinomas de mama, inclusive originando terapêuticas específicas do bloqueio de sua atividade. Alguns estudos têm sugerido que a ativação aberrante da atividade quinase desses receptores desempenha papel importante no desenvolvimento e na progressão tumoral em $\mathrm{CEE}^{(1,27)}$, induzindo aumento da migração e agregação celular, assim como hiperproliferação e diferenciação de células epiteliais(1).

A expressão de EGFR é pouco estudada em CEE. Alguns estudos verificaram associação entre a superexpressão dessa proteína e características clinicopatológicas, como idade, tipo histológico, nível de infiltração e metástase linfonodal, mas não existe consenso entre esses dados. Entretanto, há concordância entre os autores quanto ao fato de a superexpressão de EGFR estar associada a menores

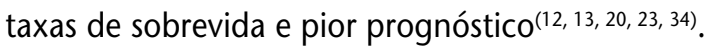

Grande parte dos poucos estudos de literatura que analisaram a expressão de c-erbB-2 relatou que a superexpressão dessa proteína não influencia o prognóstico de $\operatorname{CEE}^{(7,9,33)}$. Entretanto, Lam et al. verificaram que a superexpressão em $10 \%$ dos casos está associada a grau histológico ${ }^{(15)}$. Outro estudo mostrou que c-erbB-2 está associado a pior sobrevida ${ }^{(5)}$. Há também estudos em que não foi verificada superexpressão dessa proteína em casos de $\mathrm{CEE}^{(30,31)}$.

O objetivo deste trabalho foi estudar as expressões imuno-histoquímicas de c-erbB-2 e EGFR em amostras de carcinoma epidermóide de esôfago e correlacionar tais dados aos clinicopatológicos.

\section{Material e métodos}

\section{Casuística}

Para o estudo foram analisados 613 casos de pacientes com CEE, biopsiados ou operados no Centro de Pesquisa e Tratamento Hospital do Câncer A.C. Camargo, em São Paulo, de 1980 até 1999 . Todos os casos foram revistos em relação aos dados demográficos e clinicopatológicos.

Os 613 casos, representados por 861 amostras (595 peças cirúrgicas e 266 biópsias), foram analisados de duas formas distintas. As 427 amostras, compostas por 425 peças cirúrgicas e duas biópsias endoscópicas, foram submetidas a reações de imuno-histoquímica e análises através da técnica de tissue microarray (TMA). Em 434 exemplares (264 biópsias e 170 peças cirúrgicas que não continham material suficiente para a construção do TMA), as reações e análises foram feitas separadamente em corte convencional.

\section{Construção do TMA}

Para o estudo foram construídos três blocos de TMA, cada um contendo 288 cores de $1 \mathrm{~mm}$, sendo o primeiro core representado por um fragmento de fígado normal utilizado como referência. Em cada bloco foram incluídas cerca de 143 amostras de casos distintos de CEE com diferentes graus de diferenciação e comportamentos biológicos, dispostas em duplicata, correspondendo a áreas diferentes da mesma amostra. Com os blocos de TMA prontos, foram obtidos cortes de $3 \mu \mathrm{m}$ de espessura, colhidos em lâminas com adesivos especiais para a técnica (Instrumedics Inc.). O TMA foi construído utilizando o Manual Tissue Arrayer I, aparelho fabricado e adquirido pela Beecher Instruments Inc. 


\section{Imuno-histoquímica}

Duas lâminas de cada bloco de TMA, com cortes em dois níveis e cerca de 40 cortes de diferença entre elas, foram submetidas às reações de imuno-histoquímica. Nos casos em que as reações e análises foram feitas em corte convencional, a reação imuno-histoquímica foi realizada em apenas uma lâmina. Considerando que cada caso podia estar sendo representado por mais de uma amostra, tanto em TMA quanto em corte convencional, foram então obtidas de uma a 16 análises imuno-histoquímicas em cada caso. Ou seja, se um bloco de TMA contém quatro amostras diferentes de um mesmo caso, em duplicata, ao avaliar duas lâminas desse bloco obtemos 16 análises imuno-histoquímicas para esse determinado caso.

As reações de imuno-histoquímica foram realizadas pela técnica de complexo estreptavidina-biotina-peroxidase (StreptABC, DAKO). Após desparafinização dos cortes dos tecidos, foi feita a recuperação antigênica utilizando panela de pressão, em tampão citrato $\mathrm{pH}$ 6.0, seguida pelo bloqueio de peroxidase endógena, com solução de peróxido de hidrogênio a $3 \%$. Os cortes foram incubados com os anticorpos primários c-erbB-2 policlonal (1:500, A0485, DAKO) e EGFR monoclonal (1:20, NCL-EGFR-384, Novocastra). Em seqüência, as lâminas foram incubadas com o anticorpo secundário biotinilado, seguidas por incubação com o Streptavidina HRP (Kit LSAB+ peroxidase, K0690, DAKO). As reações foram reveladas com diaminobenzidina (kit Liquid DAB + Substrate, K3468, DAKO) e contracoradas com hematoxilina de Harris (Merck).

Os resultados da análise da expressão imuno-histoquímica de ambos os marcadores foram baseados na intensidade e no padrão da marcação das células tumorais, divididas em quatro categorias: nenhuma marcação ou marcação fraca em menos de $10 \%$ das células tumorais (0); marcação com intensidade fraca, em parte de sua membrana, em mais de $10 \%$ das células (1+); marcação completa de membrana de intensidade fraca a moderada em mais de $10 \%$ das células (2+) e marcação de intensidade forte em mais de 10\% (3+). As categorias 0 e $1+$ foram consideradas negativa e 2+ e 3+, positivas, de acordo com as regras do teste reconhecido pela Food and Drug Administration (FDA): o HercepTestTM (DAKO). Em seguida, os casos foram classificados em três grupos, de acordo com os critérios: maioria das amostras com expressão 0 e/ou 1+ e nenhuma com 2+ e 3+ (grupo I: negativo), pelo menos uma amostra com expressão $2+$ e nenhuma com 3+ (grupo II: potencialmente positivo) e pelo menos um exemplar com expressão 3+ (grupo III: positivo).

\section{Análise estatística}

A análise estatística foi feita através dos programas de computador Stata Statistical Software, versão 7.0, Stata Corporation e SPSS for Windows, versão 10.0, SPSS Inc., utilizando o teste do qui-quadrado ou o teste exato de Fisher. As análises de sobrevida global foram realizadas de duas formas. Primeiramente, foi realizada a análise de sobrevida global para todo o período de seguimento dos casos, considerando a data de admissão no serviço como ponto inicial e a data de óbito, ou último retorno, como ponto final. $\mathrm{O}$ cálculo da estimativa de sobrevida global foi realizado pela técnica de Kaplan-Meier, e as comparações entre as curvas de sobrevida em relação as variáveis estudadas, pelo teste de log-rank. A análise multivariada foi feita pelo modelo de riscos proporcionais de Cox. Para todas as análises, foram considerados significativos os valores de $\alpha<0,05$. Para viabilizar alguns cálculos estatísticos, foi necessário agrupar algumas categorias, como ocorreu no caso de c-erbB-2 e EGFR, em que os grupos II e III foram reunidos como positivos. No grau histológico também houve rearranjo dos dados, sendo agrupadas as categorias G1/G2 e G3/G4.

\section{Resultados}

\section{Dados clinicopatológicos dos pacientes}

Os dados clinicopatológicos estão sumariados na Tabela 1. Entre os 613 casos de carcinoma epidermóide de esôfago selecionados para esse estudo, 504 (82,2\%) são do sexo masculino e $109(17,8 \%)$, do feminino, com predominância de indivíduos de etnia branca (68\%). A faixa de idade dos pacientes variou de 32 a 94 anos, com idade média de 59,2 anos e mediana de 59 anos.

A maioria dos casos $(57,4 \%)$ apresentou a lesão no terço médio do esôfago e, de acordo com o grau histológico, 49\% foram classificados como moderadamente diferenciados (G2). Em relação à categoria pT, os 206 casos representados por peças cirúrgicas mostraram alta incidência $(69,1 \%)$ de tumores que atingiram a adventícia (pT3). Essa avaliação não foi feita nas biópsias devido ao tamanho reduzido das amostras tumorais, o que não permitiu avaliação precisa da profundidade de invasão. Tal limitação também foi encontrada na avaliação da invasão vascular, sendo considerados somente os casos com peças cirúrgicas. Assim, invasão vascular foi vista em 151 (73,3\%) casos; invasão linfática foi observada em 116 (56,5\%) e invasão venosa, em apenas três (1,5\%). A grande maioria dos casos evoluiu para morte $(82,2 \%)$. 


\section{Sumário dos dados clinicopatológicos dos 613 casos de CEE analisados nesse estudo}

\begin{tabular}{|c|c|c|}
\hline Variável & Categoria & Número de casos (\%) \\
\hline \multirow[t]{2}{*}{ Gênero ( $n=613$ ) } & Masculino & $504(82,2)$ \\
\hline & Feminino & $109(17,8)$ \\
\hline \multirow[t]{5}{*}{ Cor $(n=613)$} & Negro & $59(9,6)$ \\
\hline & Pardo & $101(16,5)$ \\
\hline & Amarelo & $19(3)$ \\
\hline & Branco & 417 (68) \\
\hline & Indeterminada & $17(2,8)$ \\
\hline \multirow{5}{*}{$\begin{array}{l}\text { Grau de diferenciação } \\
(n=613)\end{array}$} & Bem diferenciado (G1) & $159(26,1)$ \\
\hline & Moderadamente diferenciado (G2) & $300(49,1)$ \\
\hline & Pouco diferenciado (G3) & $149(24,3)$ \\
\hline & Indiferenciado (G4) & $2(0,3)$ \\
\hline & Não classificado (GX) & $3(0,4)$ \\
\hline \multirow[t]{4}{*}{ Sítio $(n=613)$} & Superior & $130(21,2)$ \\
\hline & Médio & $352(57,4)$ \\
\hline & Inferior & $110(18)$ \\
\hline & Sem dados & $21(3,4)$ \\
\hline \multirow{6}{*}{$\begin{array}{l}\text { Invasão vascular* } \\
(n=206)\end{array}$} & Venosa & $35(17)$ \\
\hline & Venosa (isolada) & $3(1,5)$ \\
\hline & Linfática & $148(71,8)$ \\
\hline & Linfática (isolada) & $116(56,6)$ \\
\hline & Linfática/venosa & $32(15,5)$ \\
\hline & Não observada & $55(26,7)$ \\
\hline \multirow[t]{4}{*}{$\mathrm{pT}^{*}(n=204)$} & $\mathrm{T} 1$ & $9(4,4)$ \\
\hline & T2 & $46(22,6)$ \\
\hline & T3 & $141(69,1)$ \\
\hline & T4 & $8(3,9)$ \\
\hline \multirow{5}{*}{$\begin{array}{l}\text { Evolução da doença } \\
(n=612)\end{array}$} & Vivos com a doença & $3(0,5)$ \\
\hline & Vivos sem a doença & $14(2,3)$ \\
\hline & Morte devida à doença & $503(82,2)$ \\
\hline & Morte devida a outras causas & $6(1)$ \\
\hline & Perdidos de vista & $86(14,1)$ \\
\hline
\end{tabular}

${ }^{*}$ Considerados apenas os casos representados por peças cirúrgicas.

\section{Análise imuno-histoquímica}

As expressões de c-erbB-2 e EGFR foram avaliadas em 597 e em 585 casos, respectivamente. Alguns casos não foram avaliados devido à ausência de tumor na amostra ou ao desprendimento do corte da amostra da lâmina. A análise imunohistoquímica de c-erbB-2 mostrou três grupos distintos, de acordo com sua expressão: negativos (grupo l) em 344 (57,6\%) casos, potencialmente positivos (grupo II) em 206 (34,5\%) e positivos (grupo III) em 47 (7,9\%) (Figura 1). Essa classificação também pôde ser observada na expressão de EGFR, sendo que 131 (22,4\%) casos se enquadraram no grupo l; 310 (53\%), no grupo II e 144 (24,6\%), no grupo III (Figura 2). 


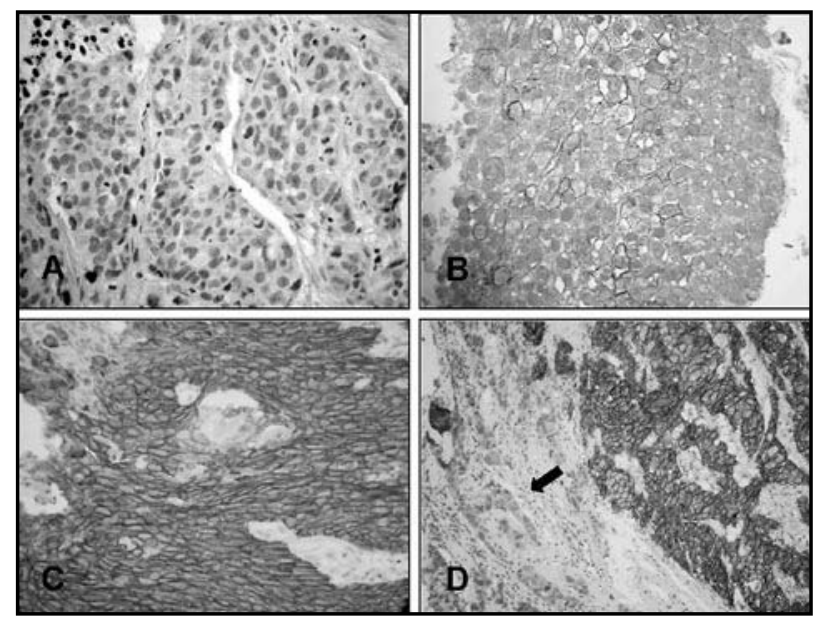

Figura 1 - Imuno-histoquímica demonstrando marcação de membrana de c-erbB-2 em (EE. A) amostra revela negatividade para expressão dessa proteína, aumento original 400x; B) caso positivo 2+, aumento original 400x; C) marcação positiva 3+, aumento $400 x$ e D) caso positivo 3 + e áreas tumorais sem expressão de c-erbB-2 (seta), aumento original $200 x$

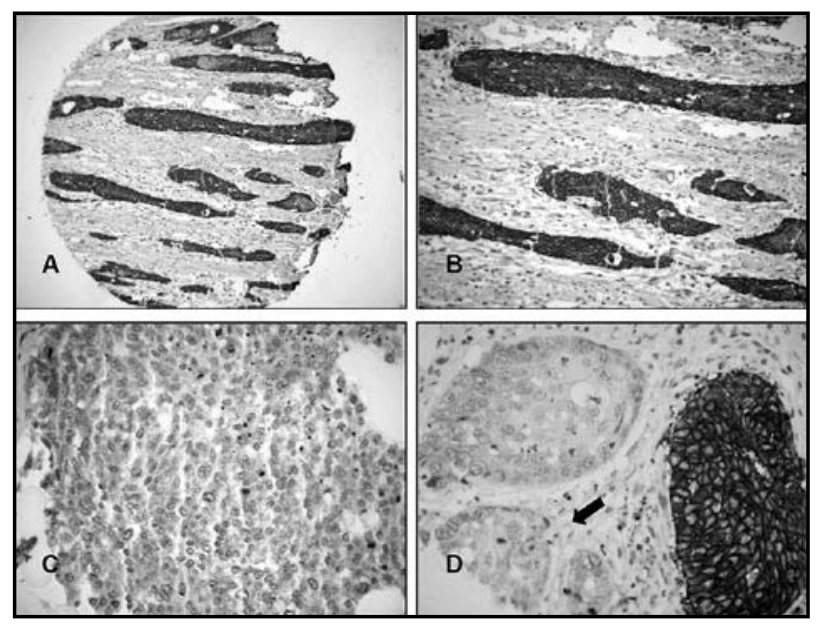

Figura 2 - Imuno-histoquímica mostrando marcação de EGFR em membrana, em CEE. A) core do TMA, com marcação positiva 3+, aumento original 100x e B) em 200x; C) amostra com marcação negativa para EGFR, aumento 200x; D) áreas com marcação $2+($ seta) e $3+$, aumento original $400 x$

Os resultados obtidos mostraram a existência de correlação estatisticamente significativa entre as coexpressões dos dois marcadores avaliados $(p=0,0001)$.

\section{Correlação com dados clinicopatológicos}

A correlação das expressões de c-erbB-2 e de EGFR com os dados clinicopatológicos está sumariada na Tabela 2. As expressões de c-erbB-2 e de EGFR não se relacionaram com gênero, etnia, sítio, nível de invasão, invasão vascular, recorrência, evolução da doença, sobrevidas global e livre de doença. No entanto, houve correlação significativa entre as expressões de c-erbB-2 $(p=0,04)$ e EGFR $(p=0,03)$ e o grau histológico. Ambos os marcadores foram significativamente mais expressos em casos bem/moderadamente diferenciados do que nos pouco diferenciados (Tabela 2).

\section{Sobrevida global}

A análise de sobrevida global nos casos de CEE mostrou estimativas de sobrevida consideravelmente baixas em dois, cinco e 10 anos de 19,3\%,8\% e 5,3\%, respectivamente. Não foi observada correlação entre a sobrevida global e a expressão de EGFR $(p=0,230)$ e c-erbB-2 $(p=0,756)$ (Figura 3).

\section{Discussão}

A análise da expressão imuno-histoquímica dos receptores de fatores de crescimento epidérmico mostrou que cerca de $42 \%$ e $78 \%$ dos casos apresentaram expressão positiva para c-erbB-2 e EGFR, respectivamente. Existem poucos trabalhos que relacionam a expressão de c-erbB-2 e EGFR com o CEE, apresentando freqüências discrepantes que variam de $0 \%$ a $64 \%$ para c-erbB- $2^{(7,9,15,30,31)}$, e de $42,5 \%$ a $70 \%$ para $\operatorname{EGFR}^{(7,12,13,34)}$. Tal discrepância pode ser devida a diferenças na técnica imuno-histoquímica, origens distintas dos anticorpos usados pelos diferentes autores ou, até mesmo, ao critério utilizado para classificação da expressão imuno-histoquímica dessas proteínas e a categorização dos casos, com diferentes cut-offs. Neste trabalho, nós levamos em consideração as regras do teste reconhecido pela FDA: o HercepTestTM (DAKO).

Através de análises estatísticas em nossos dados, foi constatada correlação significativa entre as expressões de EGFR e c-erbB-2 e o grau histológico, em que casos considerados bem/moderadamente diferenciados expressaram ambos os marcadores mais freqüentemente do que os casos pouco diferenciados/indiferenciados. Nossos dados mostraram-se similares aos de Itakura et al., que observaram correlação significativa entre superexpressão de EGFR e grau histológico(13).

Outras correlações entre a expressão de EGFR e variáveis clinicopatológicas, como idade, gênero, sítio tumoral, invasões venosa e linfática e sua influência na sobrevida global não se mostraram significativas nesse estudo, diferindo dos de outros autores que mostraram tais associações, embora esses sejam trabalhos abrangendo poucos casos, de constituição étnica diferente e com resultados controversos ${ }^{(12,13,20,23,34)}$.

Há trabalhos que têm relatado que o padrão de distribuição da expressão de EGFR, classificado como padrão homo- 


\begin{tabular}{|c|c|c|c|c|c|c|c|}
\hline Tabela 2 & ressoes o & $-\angle \mathrm{eE}$ & 1 CEE e & correl & com dat & micopatc & \\
\hline Variável & Categoria & & c-erbB-2 & & & EGFR & \\
\hline & & $N(\%)$ & $P(\%)$ & $p$ & $N(\%)$ & $\mathrm{Pa}(\%)$ & $p$ \\
\hline Gênero & Masculino & $281(81,7)$ & $209(82,6)$ & 0771 & $109(83,2)$ & $374(82,4)$ & \\
\hline$(n=597 / 585)$ & Feminino & $63(18,3)$ & $44(17,4)$ & $0, / / 1$ & $22(16,8)$ & $80(17,6)$ & $0,8<6$ \\
\hline Cor & Branca & $236(70,7)$ & $170(68,8)$ & 0631 & $84(67,2)$ & $314(70,9)$ & 0127 \\
\hline$(n=581 / 568)$ & Não-branca & $98(29,3)$ & $77(31,2)$ & 0,034 & $41(32,8)$ & $129(29,1)$ & $0,4 \angle 1$ \\
\hline Sítio & Superior & $67(20,2)$ & $60(24,4)$ & 0067 & $26(20,8)$ & $96(21,8)$ & 0178 \\
\hline$(n=578 / 565)$ & Inferior & $54(16,3)$ & $53(21,5)$ & $0,00 /$ & $18(14,4)$ & $82(18,6)$ & $0,4 / 0$ \\
\hline & Médio & $211(63,5)$ & $133(54,1)$ & & $81(64,8)$ & $262(59,6)$ & \\
\hline Grau de & G1/G2 & $246(71,9)$ & $201(79,8)$ & Q ר?ח & $90(68,7)$ & $351(77,6)$ & 0036 \\
\hline $\begin{array}{l}\text { diferenciação } \\
(n=594 / 583)\end{array}$ & G3/G4 & $96(28,1)$ & $51(20,2)$ & $0, v<9$ & $41(31,3)$ & $101(22,4)$ & , \\
\hline Invasão linfática & Não observada & $36(29,5)$ & $19(24,1)$ & & $13(25,5)$ & $39(26,4)$ & \\
\hline$(n=199)$ & Presente & $86(70,5)$ & $60(75,9)$ & $0,39 /$ & $38(74,5)$ & $109(73,6)$ & 0,904 \\
\hline Invasão venosa & Não observada & $101(82,8)$ & $66(83,5)$ & & $42(82,4)$ & $122(82,4)$ & \\
\hline$(n=199)$ & Presente & $21(17,2)$ & $13(16,5)$ & 0,৪৪9 & $9(17,6)$ & $26(17,6)$ & 0,99 \\
\hline pTb, c $(n=197)$ & $1 / 2$ & $29(53,7)$ & $25(46,3)$ & & $15(30)$ & $37(25,2)$ & \\
\hline & $3 / 4$ & $91(62,8)$ & $54(37,2)$ & 0,246 & $35(70)$ & $110(74,8)$ & 0,503 \\
\hline
\end{tabular}

N: negativo; P: positivo; p: valor de p; para análises estatísticas, os grupos II e III foram agrupados como positivos; para cálculos estatísticos, as categorias foram agrupadas; cconsideradas apenas as peças cirúrgicas.

gêneo/heterogêneo ou mosaico/difuso, está correlacionado a estadiamento, grau histológico, nível de invasão ${ }^{(13)}$, além de $\mathrm{pN}$ e sobrevida global ${ }^{(13,34)}$. Tal análise sobre o padrão de distribuição da expressão imuno-histoquímica desse marcador e sua relação com prognóstico em CEE não foi realizada em nosso trabalho, uma vez que optamos pelo método similar ao padronizado para c-erbB-2.

Em relação a c-erbB-2, apenas Lam et al. verificaram a existência de correlação estatisticamente significativa entre essa proteína e grau de diferenciação, corroborando nossos resultados, apesar da baixa freqüência de casos (10\%) com superexpressão encontrada por esses autores ${ }^{(15)}$.

Apesar de a diferença não ter sido estatisticamente significativa, foi observado que c-erbB-2 foi mais expressa em casos em que a lesão encontrava-se no terço médio do esôfago. A explicação para tal associação pode estar mais relacionada à mera questão de distribuição do número de casos envolvidos do que ao comportamento biológico da doença. Essa relação não foi observada em outros estudos com c-erbB-2: a maioria deles afirma que essa proteína não se relaciona com características clinicopatológicas, não influenciando o prognóstico de $\operatorname{CEE}^{(7,9,33)}$.

No que diz respeito às expressões de EGFR e c-erbB-2, acredita-se que a atividade descontrolada desses recepto- res esteja envolvida no desenvolvimento e na progressão tumoral em CEE, estimulando a hiperproliferação das células epiteliais. A heterodimerização entre c-erbB-2 e os demais integrantes da família dos receptores de fatores de crescimento epidérmico, principalmente EGFR, proporciona indução mais potente para proliferação celular, contribuindo para o desenvolvimento tumoral(22, 26, 27).

Nossas análises mostraram a existência de correlação significativa entre a coexpressão de c-erbB-2 e EGFR $(p=0,0001)$, em que casos com alta positividade para EGFR também apresentaram expressão de c-erbB-2, indicando a ação conjunta desses dois receptores como heterodímeros. Nossos dados foram diferentes dos apresentados por Friess et al., que não mostraram correlação significativa. Porém, o modo de análise dos resultados da expressão imuno-histoquímica desses autores não foi semelhante ao nosso, o que poderia ter causado essa discrepância entre os $\operatorname{dados}^{(7)}$.

Nossos dados mostraram associação entre a superexpressão de c-erbB-2 e EGFR com tumores mais diferenciados e, portanto, menos agressivos, sugerindo que a superexpressão dessas proteínas podem estar relacionadas a uma outra função biológica, que não a proliferação celular, como a indução de diferenciação celular, ou a outro evento que possa estar ocorrendo concomitantemente à proliferação 


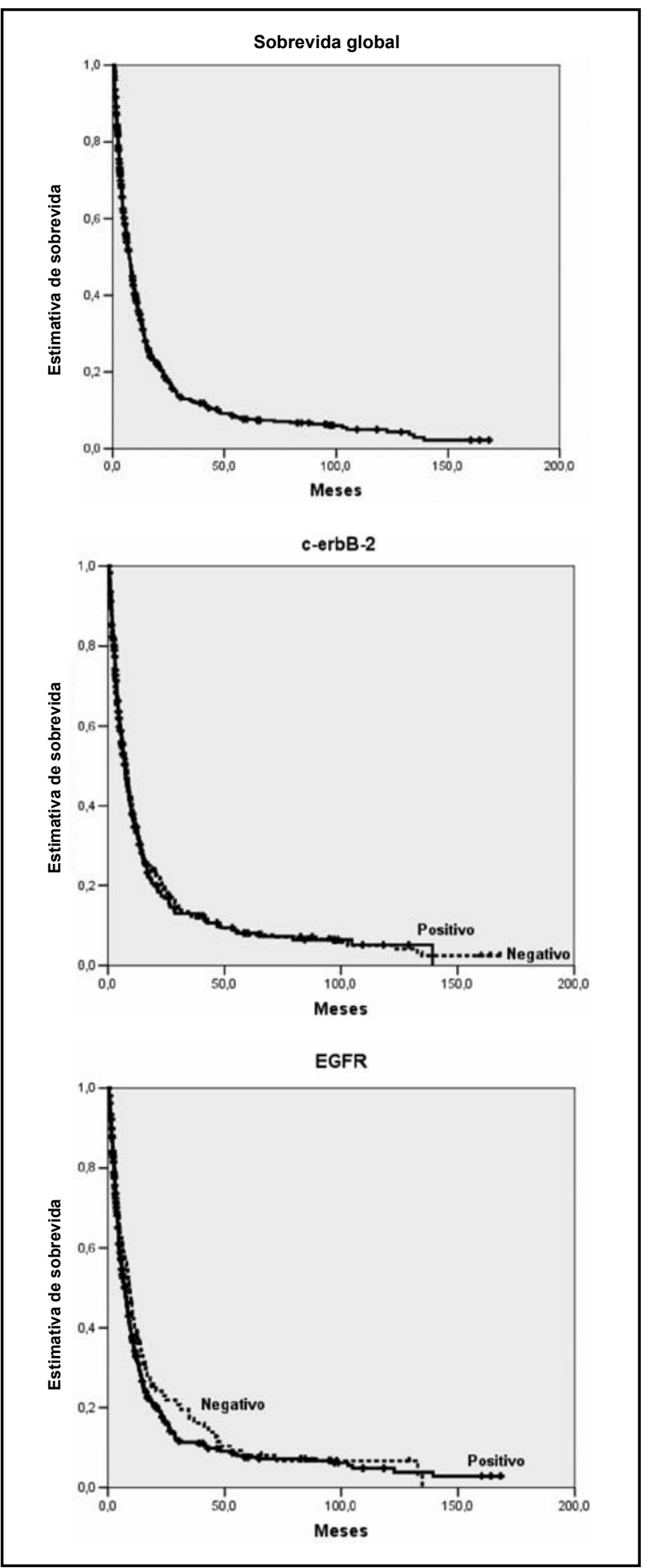

Figura 3 - Sobrevida global. A) curva de sobrevida global dos casos de (EE estudados; B) curva de sobrevida global em relação à expressão de c-erbB-2 $(p=0,756)$; $C)$ curva de sobrevida global em relação à expressão de $\operatorname{EGFR}(p=0,23)$

celular, mascarando o efeito proliferativo na população de células tumorais. Seriam necessárias análises adicionais envolvendo outras proteínas, como o indicador de proliferação celular Ki-67 e outras relacionadas a processos que possam estar associadas à expressão desses receptores, além de estudos de amplificação gênica através de hibridização in situ, para a melhor compreensão do papel dessas proteínas na carcinogênese de CEE.

Ainda, existem indícios de que a superexpressão de EGFR estaria associada a hiperproliferação em estádios pré-malignos e precoces de $\operatorname{CEE}(1)$, não sendo tão relevantes para a avaliação prognóstica em casos mais avançados, como mostram nossos resultados. Entretanto, seria necessária a análise de lesões precursoras de CEE para a verificação de tal associação, o que não foi realizado no presente trabalho.

Um dos grandes problemas dos testes de imuno-histoquímica é que se trata de técnica trabalhosa e relativamente cara, o que faz com que os trabalhos sejam realizados com poucos casos, não sejam testados em duplicata e triplicata e sejam pouco reprodutíveis. Recentemente, com o advento da técnica TMA é possível que esses problemas sejam minimizados, uma vez que centenas de amostras de tecidos podem ser dispostas numa única lâmina, em cilindros de 0,6-1 mm, permitindo a análise simultânea de vários tecidos por métodos de imuno-histoquímica e hibridizações in situ para estudos em nível de ácido desoxirribonucleico (DNA), ácido ribonucleico (RNA) e proteínas. Isso também minimizaria possíveis variações da técnica entre as amostras, com racionalização dos custos e tempo despendido, possibilitando a realização das reações de forma repetida, à similaridade de outras técnicas experimentais, e a expressão do resultado pela resultante dos experimentos $(10,11,17,19,24,29)$. No entanto, uma das principais críticas a essa metodologia questiona se uma amostra de alguns milímetros de diâmetro pode ser representativa de toda a amostra tumoral devido à existência de heterogeneidade tecidual. Tal problema pode ser controlado se mais de um cilindro de cada amostra tecidual forem utilizados, com a finalidade de aumentar a representatividade da amostra ${ }^{(10,19,24,29)}$. Nesse sentido, alguns trabalhos têm relatado concordância de cerca de $90 \%$ quando comparados os resultados de análise em TMA e em corte inteiro convencional, mostrando que a técnica de tissue microarray pode ser um instrumento de confiança para estudos em tecidos tumorais ${ }^{(10,11,17,19,24,29)}$. Tal comparação entre os resultados provenientes da técnica de TMA e em corte convencional não foram realizados em nosso estudo.

Concluindo, nosso estudo demonstrou associação estatisticamente significativa entre as expressões imunohistoquímicas de c-erbB-2 e EGFR e o grau histológico em carcinoma epidermóide do esôfago, sem correlação com outros fatores. Nossos resultados podem sugerir a participação dessas proteínas na diferenciação tumoral. Outros estudos, incluindo análise de amplificação gênica, são necessários para melhor compreensão da superexpressão de c-erbB-2 e EGFR na carcinogênese de CEE e sua influência 


\section{Referências}

1. ANDL, C.D. et al. Epidermal growth factor receptor mediates increased cell proliferation, migration, and aggregation in esophageal keratinocytes in vitro and in vivo. $\mathrm{J} \mathrm{Biol}$ Chem, v. 278, n. 3, p. 1824-30, 2003.

2. CHANG, F. et al. Screening for human papillomavirus infections in esophageal squamous cell carcinomas by in situ hybridization. Cancer, v. 72, n. 9, p. 2525-30, 1993.

3. CHINO, O. et al. Clinicopathological studies of esophageal carcinoma in achalasia: analyses of carcinogenesis using histological and immunohistochemical procedures. Anticancer Res, v. 20, n. 5C, p. 3717-22, 2000.

4. DIETZ, J. et al. Fatores de risco relacionados ao câncer de esôfago no Rio Grande do Sul. Rev Assoc Med Bras, v. 44, n. 4, p. 269-72, 1998.

5. DREILICH, M. et al. HER-2 overexpression (3+) in patients with squamous cell esophageal carcinoma correlates with poorer survival. Dis Esophagus, v. 19, n. 4, p. 224-31, 2006.

6. ENGEL, L.S. et al. Population-attributable risks of esophageal and gastric cancers. J Natl Cancer Inst, v. 95, n. 18, p. 1404-13, 2003.

7. FRIESS, H. et al. Concomitant analysis of the epidermal growth factor receptor family in esophageal cancer: overexpression of epidermal growth factor receptor mRNA but not of c-erbB-2 and c-erbB-3. World J Surg, v. 23, n. 10, p. 1010-8, 1999.

8. FUJITA, H. et al. Mortality and morbidity rates, postoperative course, quality of life, and prognosis after extended radical lymphadenectomy for esophageal cancer. Comparison of three-field lymphadenectomy with two-field lymphadenectomy. Ann Surg, v. 222, n. 5, p. 654-62, 1995.

9. HARDWICK, R.H. et al. Immunohistochemical detection of p53 and c-erbB-2 in oesophageal carcinoma; no correlation with prognosis. Eur J Surg Oncol, v. 23, n. 1, p. 30-5, 1997.

10. HOOS, A.; CORDON-CARDO, C. Tissue microarray profiling of cancer specimens and cell lines: opportunities and limitations. Lab Invest, v. 81, n. 10, p. 1331-8, 2001.

11. HSU, F.D. et al. Tissue microarrays are an effective quality assurance tool for diagnostic immunohistochemistry. Mod Pathol, v. 15, n. 12, p. 1374-80, 2002.

12. INADA, S. et al. Evaluation of malignancy and the prognosis of esophageal cancer based on an immunohistochemical study ( 553 , E-cadherin, epidermal growth factor receptor). Surg Today, v. 29, n. 6, p. 493-503, 1999.

13. ITAKURA, Y. et al. Epidermal growth factor receptor overexpression in esophageal carcinoma. An immunohistochemical study correlated with clinicopathologic findings and DNA amplification. Cancer, v. 74, n. 3, p. 795-804, 1994.

14. KUWANO, $\mathrm{H}$. et al. Distinctive clinicopathological characteristics in esophageal squamous cell carcinoma. Ann Thorac Cardiovasc Surg, v. 9, n. 1, p. 6-13, 2003.

15. LAM, K.Y. et al. C-erbB-2 protein expression in oesophageal squamous epithelium from oesophageal squamous cell carcinomas, with special reference to histological grade of carcinoma and pre-invasive lesions. Eur J Surg Oncol, v. 24, n. 5, p. 431-5, 1998.

16. MARGER, R.S.; MARGER, D. Carcinoma of the esophagus and tylosis: a lethal genetic combination. Cancer, v. 72, n. 1, p. 17-9, 1993.

17. MILANES-YEARSLEY, M. et al. Tissue micro-array: a cost and time-effective method for correlative studies by regional and national cancer study groups. Mod Pathol, v. 15, n. 12, p. 1366-73, 2002.

18. MINISTÉRIO DA SAÚDE. Estimativa 2005: incidência de câncer no Brasil. Rio de Janeiro: INCA, 2005.

19. $\mathrm{MOCH}, \mathrm{H}$. et al. Tissue microarrays: what will they bring to molecular and anatomic pathology? Adv Anat Pathol, v. 8, n. 1, p. 14-20, 2001.

20. MUKAIDA, H. et al. Clinical significance of the expression of epidermal growth factor and its receptor in esophageal cancer. Cancer, v. 68, n. 1, p. 142-8, 1991.

21. NAKAGAWA, S. et al. Recurrence pattern of squamous cell carcinoma of the thoracic esophagus after extended radical esophagectomy with three-field lymphadenectomy. J Am Coll Surg, v. 198, n. 2, p. 205-11, 2004.

22. OLAYIOYE, M. A. et al. The ErbB signaling network: receptor heterodimerization in development and cancer. EMBO J, v. 19, n. 13, p. 3159-67, 2000.

23. OZAWA, S. et al. Prognostic significance of epidermal growth factor receptor in esophageal squamous cell carcinomas. Cancer, v. 63, n. 11, p. 2169-73, 1989.

24. RIMM, D.L. et al. Amplification of tissue by construction of tissue microarrays. Exp Mol Pathol, v. 70, n. 3, p. 255-64, 2001.

25. ROSAI, J. Gastrointestinal tract. In: ROSAI, J.; ACKERMAN, L.V. (eds.). Rosai and Ackerman's Surgical Pathology. London: Mosby, 2004.

26. ROSKOSKI, R. Jr. The ErbB/HER receptor protein-tyrosine kinases and cancer. Biochem Biophys Res Commun, v. 319, n. 1, p. 1-11, 2004.

27. ROWINSKY, E.K. Signal events: cell signal transduction and its inhibition in cancer. Oncologist, v. 8, suppl 3, p. 5-17, 2003.

28. SAGAR, P.M. Aetiology of cancer of the oesophagus: geographical studies in the footsteps of Marco Polo and beyond. Gut, v. 30, n. 5, p. 561-4, 1989.

29. SIMON, R.; SAUTER, G. Tissue microarrays for miniaturized high-throughput molecular profiling of tumors. Exp Hematol, v. 30, n. 12, p. 1365-72, 2002.

30. SUO, Z. et al. Lack of expression of c-erbB-2 oncoprotein in human esophageal squamous cell carcinomas. Anticancer Res, v. 15, n. 6B, p. 2797-8, 1995.

31. SUWANAGOOL, P. et al. Expression of c-erbB-2 oncoprotein in primary human tumors: an immunohistochemistry study. Asian Pac J Allergy Immunol, v. 11, n. 2, p. 119-22, 1993.

32. TACHIBANA, M. et al. Clinical outcomes of extended esophagectomy with three-field lymph node dissection for esophageal squamous cell carcinoma. Am J Surg, v. 189, n. 1, p. 98-109, 2005. 
33. WANG, L.S. et al. Prognosis of esophageal squamous cell carcinoma: analysis of clinicopathological and biological factors. Am J Gastroenterol, v. 94, n. 7, p. 1933-40, 1999.

34. YANO, H. et al. Immunohistologic detection of the epidermal growth factor receptor in human esophageal squamous cell carcinoma. Cancer, v. 67, n. 1, p. 91-8, 1991.

35. ZHOU, X.B. et al. Detection of human papillomavirus in Chinese esophageal squamous cell carcinoma and its adjacent normal epithelium. World J Gastroenterol, v. 9, n. 6, p. 1170-3, 2003. 